\title{
Repercussions of chronic protein-calorie malnutrition on glucose homeostasis in the rat
}

\author{
W. Okitolonda, S.M. Brichard and J.C. Henquin \\ Unité de Diabétologie et Nutrition, Faculty of Medicine, University of Louvain, Brussels, Belgium
}

\begin{abstract}
Summary. The characteristics, progressivity and reversibility of the changes in glucose homeostasis brought about by chronic protein-calorie malnutrition were studied in the rat. Four-week-old male rats received a control diet $(15 \%$ protein) or a low-protein diet ( $5 \%$ protein) until the age of 28 weeks. Other rats received the low-protein diet until 12-15 weeks, and then the control diet. In malnourished rats, fasting plasma glucose levels and both fasting and fed plasma insulin levels were lower than in control rats. At the age of 15 weeks, tolerance to oral glucose was slightly poorer, whereas tolerance to intravenous glucose was slightly better in rats receiving the low-protein diet than in control rats. During both tests the insulin response of malnourished rats was severely blunted. This inhibition largely exceeded the small decrease in their pancreatic insulin reserves. Similar results were obtained when the same test was repeated 9 weeks later. If the rats were transferred from a low-protein to a control diet for these 9 weeks, the changes in glucose tolerance
\end{abstract}

were partially corrected, but the insulin response remained inhibited. Though hepatic glycogen stores were increased in malnourished rats, i.v. glucagon or arginine caused a smaller rise in plasma glucose levels than in control rats. The insulin response was also impaired and, unlike the glucose response, was not restored by 6 weeks on a control diet. The hypoglycaemia induced by intravenous insulin was more sustained in malnourished than in control rats, but this abnormality was corrected by refeeding a control diet for 6 weeks. The results thus show that chronic protein-calorie malnutrition in the rat severely impairs insulin secretion, but only mildly alters glucose tolerance, likely because of an associated high sensitivity to insulin. These changes do not aggravate with time and are only partially reversed by several weeks on a control diet.

Key words: Protein-calorie malnutrition, glucose tolerance, hypoglycaemia, insulin secretion.
It has long been recognised that both hypoglycaemia $[1,2]$ and impaired glucose tolerance [2-4] can be associated with chronic malnutrition. However, these perturbations of glucose homeostasis, and those of several other endocrine systems, have usually been looked upon as secondary complications of, or adaptations to a life-threatening situation [reviews in 5,6]. More recent$1 y$, the possibility was raised [7-9] that protein-calorie malnutrition may induce permanent damage of pancreatic B cells that leads to progressive deterioration of their function. In this perspective, malnutrition is viewed as a risk factor that predisposes populations of developing countries to diabetes. After critical analysis of the case [10], it was considered that the hypothesis was plausible, but required more proof; and that animal experimentation might prove helpful.

Pigs [11], dogs [12], monkeys [13] and mainly rats [14-18] have been used to reproduce glucose intolerance and impaired insulin secretion, the two prominent features of the clinical picture in man. However, extensive characterisation of glucose homeostasis has only been performed in rats submitted to short-term malnutrition (3 weeks) [14]. In chronically malnourished animals, glucose homeostasis has been evaluated by a single test of glucose tolerance $[15,16]$ or by measuring fasting levels of plasma glucose and pancreatic hormones [17].

In the present study we have tried (1) to characterise in some detail glucose homeostasis in rats submitted to chronic protein-calorie malnutrition, (2) to determine the progressivity or regression of the alterations with the duration of malnutrition, and (3) to assess the reversal of the alterations after the animals have been returned to a normal diet.

\section{Materials and methods}

\section{Diets}

Two types of isocaloric diets (Usine d'Alimentation Rationnelle, Epinay/Orge, France) in powdered form were used. The control diet ( $15 \%$ protein) contained: $15 \%$ casein, $41.2 \%$ starch, $13.8 \%$ glucose, 
$17 \%$ cellulose, $5 \%$ corn oil and $8 \%$ vitamins and minerals. The lowprotein diet (5\% protein) contained: $5 \%$ casein, $48.7 \%$ starch, $16.3 \%$ glucose, $17 \%$ cellulose, $5 \%$ corn oil and $8 \%$ vitamins and minerals. These diets or the rats receiving them are, hereafter, referred to as P 15 or P 5 diets or rats.

\begin{abstract}
Animals
Male Wistar rats were used for all experiments. They were weaned at 21 days and received a $\mathbf{P} 15$ diet for 1 week. They were then divided into several experimental groups, matched for initial body weight. A total of 81 rats were used in two series. The first series comprised 2 groups of 15 rats which received a P 15 or P 5 diet until they were killed at the age of 16 weeks. The second series comprised 4 groups of rats $(n=12-14)$ : the first two groups received a $\mathrm{P} 15$ or a $\mathrm{P} 5$ diet until the age of 28 weeks; the third group received a P 5 diet until 15 weeks and was then returned to a P 15 diet until 28 weeks; a last group received a P 5 diet until 12 weeks and then a P 15 diet until 22 weeks. The animals were housed by groups of four. Food and water were always provided ad libitum. When the animals were killed (in the fed state), their pancreas and liver were resected, weighed and quickly frozen in liquid nitrogen.
\end{abstract}

\section{Tests}

Not all tests were performed in the same rats. The age of the animals at the time of each test, and the diets they had received are indicated in the legend to the appropriate figures. All tests started between 08.00 and 09.00 hours, after a $15 \mathrm{~h}$ fast. For the oral glucose tolerance test (OGTT), glucose ( $40 \%$ solution in water) was introduced directly into the stomach through a fine gastric catheter, at a dose of $2 \mathrm{~g} / \mathrm{kg}$ body weight (BW). For the intravenous glucose tolerance test (IVGTT), glucose was injected at a dose of $1 \mathrm{~g} / \mathrm{kg} \mathrm{BW}$. For the glucagon test, glucagon hydrochloride (Novo, Bagsvaerd, Denmark) $(5 \mu \mathrm{g} / \mathrm{ml})$ was injected intravenously at a dose of $5 \mu \mathrm{g} / \mathrm{kg}$ BW. For the insulin test, pork insulin (Actrapid MC, Novo) $(10 \mu \mathrm{g} / \mathrm{ml}$ ) was injected intravenously at a dose of $10 \mu \mathrm{g} / \mathrm{kg} \mathrm{BW}$. For the arginine test, arginine hydrochloride (Merck A. G., Darmstadt, FRG) $(125 \mathrm{mg}$ base $/ \mathrm{ml}$ ) was injected intravenously at a dose of $200 \mathrm{mg}$ base $/ \mathrm{kg}$ BW. Rats were wrapped in a towel to restrain them during intravenous injections (in a vein of the tail) or blood sampling (by cutting the tip of the tail).

\section{Analytical procedures}

Plasma glucose was measured on the day of the experiment by a glucose oxidase method (Beckman, Glucose-Analyser, Fullerton, CA, USA). The samples were then kept frozen at $-20^{\circ} \mathrm{C}$ until insulin measurement by a double antibody radioimmunoassay, using rat insulin as a standard (Novo Research Institute, Bagsvaerd, Denmark). Pancreatic insulin was extracted after homogenisation and sonication of the tissue in acidified ethanol. A sample of the liver was homogenised in ice-cold $0.3 \mathrm{~mol} / 1$ sucrose buffered at $\mathrm{pH} 7.4$ with $3 \mathrm{mmol} / \mathrm{l}$ imidazole-HCl. The protein content of these homogenates and of the serum was measured [19] using bovine serum albumin as a reference. For measurement of liver glycogen [20], a sample of the tissue was first digested in $1 \mathrm{~mol} / 1 \mathrm{KOH}$ for $1 \mathrm{~h}$ at $100^{\circ} \mathrm{C}$. Glycogen was then precipitated in ethanol, redissolved in acetate buffer and eventually hydrolysed with $\alpha$-amylo-glucosidase (Boehringer, Mannheim, FRG). Glucose was then measured as described above.

\section{Presentation of results}

The glucose disappearance rate $\left(\mathrm{K}_{\mathrm{G}}\right)$ during the IVGTT was calculated from the slope of the logarithm of the glucose levels between 5 and $20 \mathrm{~min}$. The integrated glucose and insulin responses during the different tests were calculated as the areas under the curves and above fasting levels.

\section{Statistical analysis}

Results are given as means \pm SEM. Student's t-test for unpaired data was used to evaluate the statistical significance of differences between test rats (P 5) and control rats (P 15).

\section{Results}

\section{Characteristics of the rats}

When 4-week-old rats were given a P 5 diet, they stopped growing for almost 1 week, and then gained weight at a considerably smaller rate than control rats receiving a $\mathrm{P} 15$ diet. After 24 weeks on the low-protein diet, their body weight was only half that of control rats (Table 1). When $P 5$ rats were transferred to a $P 15$ diet, their body weight gain accelerated markedly, but they never caught up with the control rats (Table 1).

At the age of 16 weeks, i. e. after 12 weeks on a test diet, fed $P 5$ rats had slightly lower plasma glucose levels $(6.08 \pm 0.13$ vs $7.05 \pm 0.20 \mathrm{mmol} / 1 ; n=14 ; p<$ $0.001)$ and markedly lower plasma insulin levels $(0.90 \pm 0.04$ vs $2.44 \pm 0.22 \mathrm{ng} / \mathrm{ml} ; p<0.001)$ than $\mathrm{P} 15$ rats. The concentration of insulin in their pancreata was $22 \%$ lower than in $\mathrm{P} 15$ rats $(153 \pm 6$ vs $196 \pm$ $10 \mu \mathrm{g} / \mathrm{g} ; p<0.005$ ).

The characteristics of fed rats killed at the age of 28 weeks are given in Table 1 . In P 5 rats, the concentration of plasma proteins was decreased by $25 \%$, but no animal ever showed signs of oedema. In these fed animals, plasma glucose levels were now similar in P 15 and P 5 rats, but plasma insulin levels and, hence the insulin/glucose ratio, remained much lower in P 5 rats. The weight of their pancreata and livers was de-

Table 1. Characteristics of the rats fed a control or a low protein diet

\begin{tabular}{|c|c|c|c|}
\hline & P15 rats & P5 rats & $\mathrm{P} 5 \rightarrow \mathrm{P} 15$ rats \\
\hline Body weight (g) & $399 \pm 8$ & $205 \pm 6^{c}$ & $306 \pm 7^{c}$ \\
\hline \multicolumn{4}{|l|}{ Plasma } \\
\hline Protein $(g / 1)$ & $72.6 \pm 0.9$ & $54.0 \pm 1.4^{\mathrm{c}}$ & $64.9 \pm 1.3^{\mathrm{c}}$ \\
\hline Glucose (mmol/l) & $7.09 \pm 0.43$ & $7.09 \pm 0.22$ & $7.00 \pm 0.09$ \\
\hline Insulin (ng/ml) & $2.67 \pm 0.22$ & $1.08 \pm 0.10^{c}$ & $1.83 \pm 0.09^{6}$ \\
\hline Insulin/glucose & $0.38 \pm 0.03$ & $0.15 \pm 0.01^{c}$ & $0.26 \pm 0.01^{\mathrm{c}}$ \\
\hline \multicolumn{4}{|l|}{ Pancreas } \\
\hline Weight (g) & $1.01 \pm 0.04$ & $0.51 \pm 0.02^{\mathrm{c}}$ & $0.84 \pm 0.02^{\mathrm{c}}$ \\
\hline Weight (\% BW) & $0.25 \pm 0.01$ & $0.25 \pm 0.01$ & $0.28 \pm 0.01^{\mathrm{a}}$ \\
\hline Insulin $(\mu \mathrm{g})$ & $227 \pm 11$ & $94 \pm 3.8^{\mathrm{c}}$ & $190 \pm 6.8^{6}$ \\
\hline Insulin $(\mu \mathrm{g} / \mathrm{g})$ & $225 \pm 8.9$ & $187 \pm 9.1^{b}$ & $226 \pm 6.6$ \\
\hline \multicolumn{4}{|l|}{ Liver } \\
\hline Weight (g) & $12.7 \pm 0.32$ & $6.55 \pm 0.23^{c}$ & $10.3 \pm 0.30^{c}$ \\
\hline Weight $(\% \mathrm{BW})$ & $3.19 \pm 0.05$ & $3.19 \pm 0.05$ & $3.34 \pm 0.05^{a}$ \\
\hline Protein (g) & $2.41 \pm 0.06$ & $0.98 \pm 0.05^{\mathrm{c}}$ & $1.81 \pm 0.08^{c}$ \\
\hline Protein $(\mathrm{mg} / \mathrm{g})$ & $190 \pm 4.5$ & $150 \pm 5.9^{c}$ & $177 \pm 6.1$ \\
\hline Glycogen (mg) & $470 \pm 32$ & $322 \pm 26^{\mathrm{b}}$ & $381 \pm 21^{\mathrm{a}}$ \\
\hline Glycogen $(\mathrm{mg} / \mathrm{g})$ & $36.8 \pm 2.2$ & $48.6 \pm 3.2^{b}$ & $37.0 \pm 1.5$ \\
\hline
\end{tabular}

All values were obtained when the rats were killed. They were 28 weeks old. P15 rats had received the control diet, and P5 rats the low protein diet from the age of 4 weeks. P $5 \rightarrow$ P 15 rats had received the low protein diet between 4 and 15 weeks, and the control diet from 15 weeks onwards. Values are means for 11,12 and 13 rats respectively. Significantly different from P15 rats: ${ }^{\mathrm{a}} p<$ $0.05 ;{ }^{b} p<0.01 ;{ }^{c} p<0.001$ 

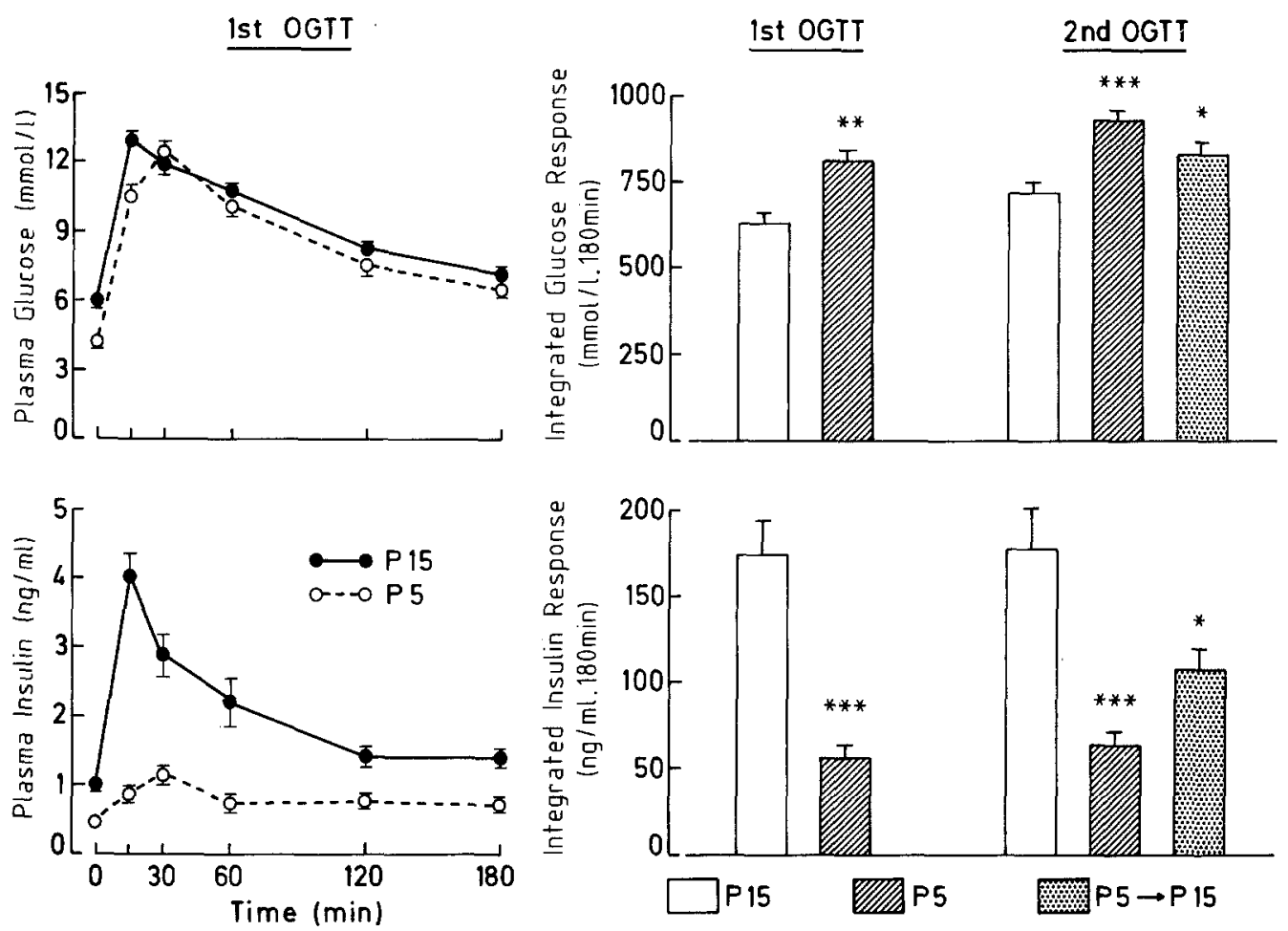

Fig. 1. Left: Plasma glucose and insulin levels during an OGTT in rats receiving a control (P 15) or a low-protein diet (P 5). Right: Integrated glucose and insulin responses during two OGTT in rats receiving a diet with the indicated protein content. Each animal underwent two tests, at the age of 15 and 24 weeks. After the first OGTT, 12 (P 5) rats were maintained on a low-protein diet, while 13 others were returned to a control diet (P 5 $\rightarrow$ P 15) for 9 weeks before undergoing the second OGTT. Values are means \pm SEM for 11 and 25 rats (1st OGTT), or for 11,12 and 13 rats (2nd OGTT). * $p<$ $0.05 ;{ }^{* * *} p<0.01 ;{ }^{* * * *} p<0.001$ vs $\mathrm{P} 15$ rats
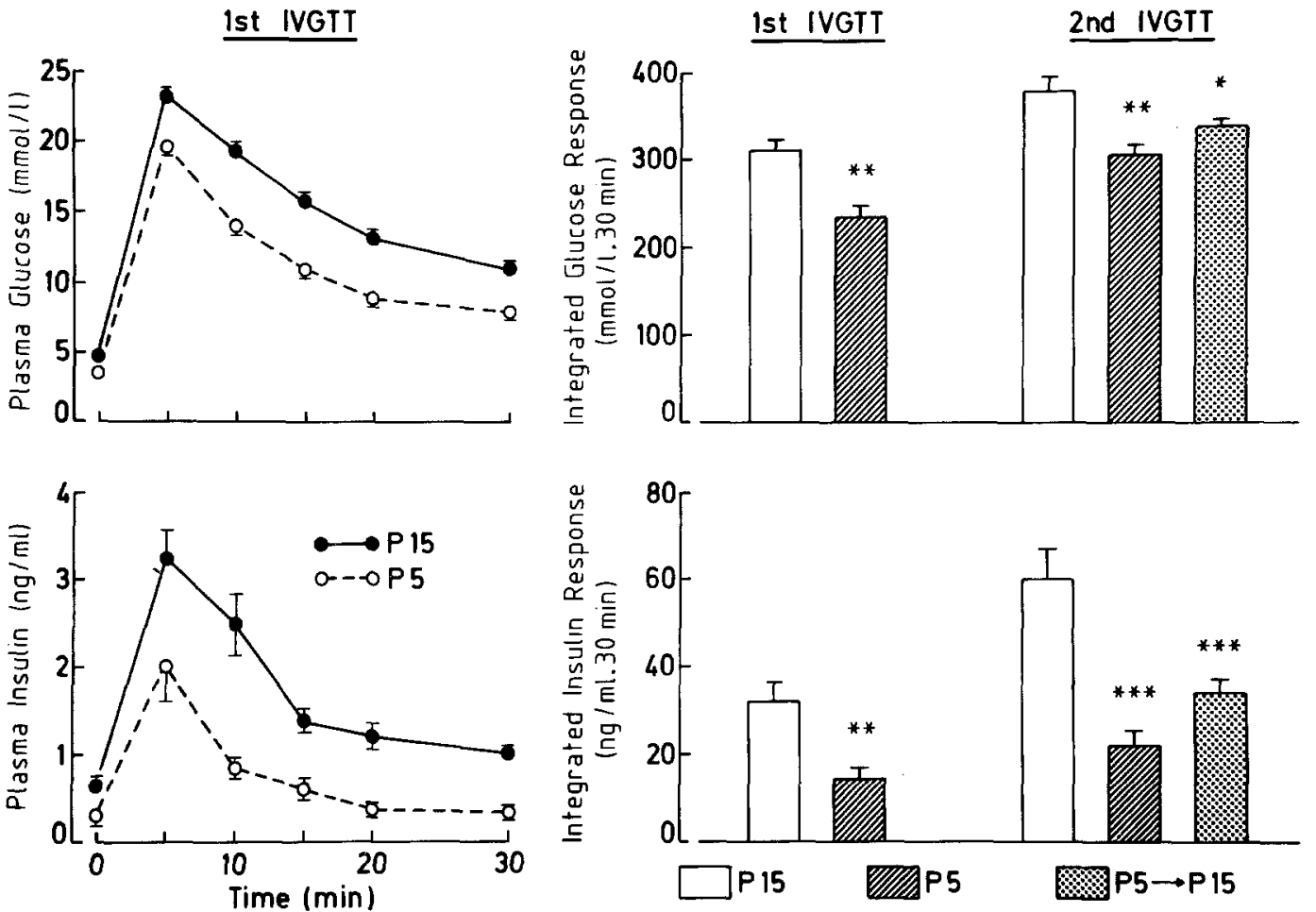

Fig. 2. Left: Plasma glucose and insulin levels during an IVGTT in rats receiving a control (P 15) or a low-protein diet (P 5). Right: Integrated glucose and insulin responses during two IVGTT in rats receiving a diet with the indicated protein content. The first test was performed in 15-weekold rats, and the second test was performed in other rats, at the age of 27 weeks.

$(\mathrm{P} 5 \rightarrow \mathrm{P} 15)$ rats had received a low-protein diet until the age of 15 weeks, and were returned to a control diet for 12 weeks before undergoing the IVGTT. Values are means \pm SEM for 15 and 14 rats ( 1 st IVGTT), or for 11,12 and 13 rats (2nd IVGTT). ${ }^{*} p<0.05 ;{ }^{* *} p<$ $0.001 ;{ }^{* * *} p<0.005$ vs $\mathrm{P} 15$ rats

creased in proportion to the decrease in body weight. As compared with $\mathrm{P} 15$ rats, pancreatic insulin concentration and liver protein concentration were decreased by 17 and $21 \%$ in P 5 rats, whereas liver glycogen concentration was increased by $32 \%$ (Table 1 ).

Feeding P 5 rats with a P 15 diet for 13 weeks failed to increase the concentration of plasma proteins to control values. Plasma insulin levels and the insulin/glucose ratio also remained lower than in $\mathrm{P} 15$ rats.
On the other hand, pancreatic insulin concentration, and liver protein and glycogen concentrations were no longer different from those measured in control P 15 rats (Table 1).

\section{Dynamic tests of glucose homeostasis}

Fasting plasma glucose and insulin concentrations were consistently lower in P 5 than in P 15 rats, regard- 

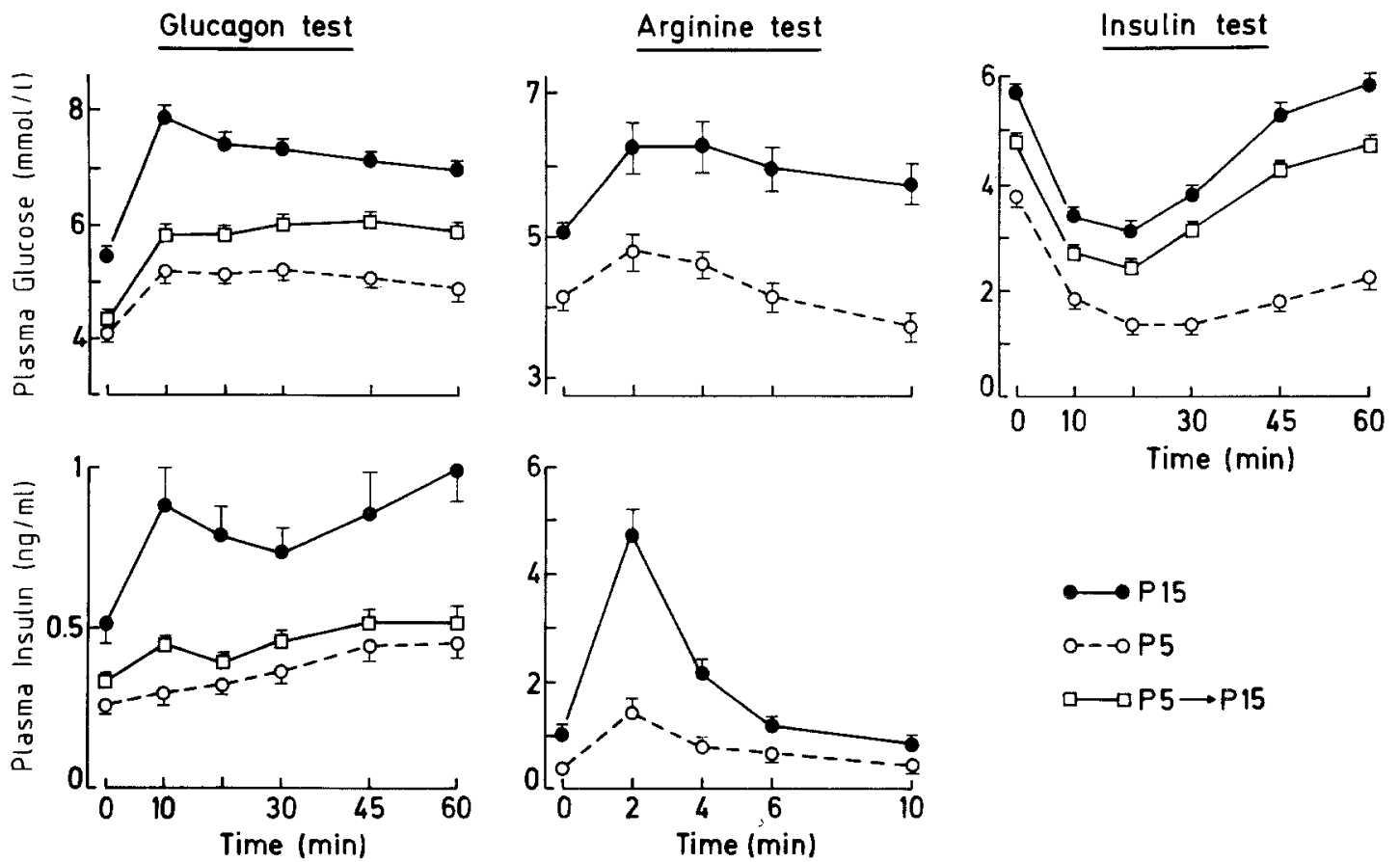

Fig.3. Plasma glucose and insulin levels during an i.v. glucagon test, an i.v. arginine test or an i.v. insulin test in rats receiving a diet with the indicated protein content. The three tests were performed on 21-, 12- and 18-week-old animals respectively. $(P$ 5 $\rightarrow P$ 15) rats had received the control diet for 6 weeks before undergoing the glucagon or the insulin test. Values are means \pm SEM for 11-15 rats

less of the age of the animals. When all values obtained at time 0 of the different tests were pooled $(n=74-88)$, the differences averaged $23 \%$ for plasma glucose $(4.06 \pm 0.06$ vs $5.26 \pm 0.07 \mathrm{mmol} / \mathrm{l})$ and $50 \%$ for plasma insulin $(0.39 \pm 0.02$ vs $0.77 \pm 0.05 \mathrm{ng} / \mathrm{ml})$. The insulin/glucose ratio was also decreased in P 5 rats as compared to $\mathrm{P} 15$ rats $(0.097 \pm 0.005$ vs $0.147 \pm 0.010$, $p<0.001$ ).

During the OGTT, plasma glucose and insulin concentrations reached a maximum value after 15 min and subsequently declined in P 15 rats, whereas the peak was only reached at $30 \mathrm{~min}$ in P 5 rats (Fig.1, left panels). Although average glucose levels were lower in P 5 than in P 15 rats, except at 30 and $60 \mathrm{~min}$, the integrated glucose response (area under the curve) was increased by about 30\% (Fig. 1, right panels). In contrast, plasma insulin levels of $\mathbf{P} 5$ rats remained considerably lower than those of $\mathrm{P} 15$ rats throughout the test, and the integrated insulin response was decreased by about $70 \%$. Similar results were obtained during a second OGTT performed 9 weeks later (Fig.1, right panels). These abnormalities were only partially reversed in P 5 rats which had been transferred to a control diet for these 9 weeks: integrated glucose response was still increased by $15 \%$ and integrated insulin response was still decreased by $40 \%$.

During the IVGTT, plasma glucose and insulin concentrations reached a maximum value at $5 \mathrm{~min}$ in both P 15 and P 5 rats, but average values were lower at all times $(p<0.005$ or less) in P 5 rats (Fig. 2, left panels). The integrated glucose and insulin responses were $24 \%$ and $55 \%$ lower in P 5 than in P 15 rats
(Fig.2, right panels), whereas the glucose disappearance rate was higher $(p<0.005)$ in P 5 rats $(4.9 \pm$ $0.3 \% / \mathrm{min})$ than in $\mathrm{P} 15$ rats $(3.8 \pm 0.2 \% / \mathrm{min})$. Similar changes were observed during a second IVGTT performed in another series of older rats (Fig. 2, right panels). For both series, the ratio of the integrated insulin to glucose responses was decreased by about $50 \%$ in P 5 rats $(0.07 \pm 0.01$ vs $0.13 \pm 0.01, p<0.001)$. In rats which had been transferred from a low-protein to a control diet $(\mathrm{P} 5 \rightarrow \mathrm{P} 15)$, the integrated glucose response remained somewhat smaller $(10 \%)$, and the integrated insulin response markedly smaller $(45 \%)$ than in control rats (Fig.2, right panels). The glucose disappearance rate was, however, no longer different from that measured in controls $(4.0 \pm 0.2$ vs $3.7 \pm 0.2 \% / \mathrm{min})$.

Intravenous injection of glucagon caused a sustained rise in plasma glucose and insulin concentrations in control rats (Fig.3). In P 5 rats, plasma glucose levels increased following a similar time-course but remained lower than in P 15 rats during the whole test, and the integrated glucose response was about $50 \%$ smaller $(50 \pm 8$ vs $104 \pm 8 \mathrm{mmol} / 1.60 \mathrm{~min}, p<0.001)$. The insulin response was much slower and smaller $(60 \%)$ than in P 15 rats (Fig. 3). Transfer of the rats to a control diet after several weeks on a low-protein diet (P 5 $\rightarrow$ P 15) slightly improved the hyperglycaemic effect of glucagon: though average plasma glucose levels remained lower than in $\mathrm{P} 15$ rats throughout, the integrated glucose response was no longer different. The insulin response was not improved, however (Fig. 3).

In $\mathrm{P} 15$ rats intravenous injection of arginine caused a rapid, marked and short-lived increase in 
plasma insulin levels, and a small rise in plasma glucose levels, that was sustained for at least $10 \mathrm{~min}$ (Fig.3). This rise was less marked and only transient in P 5 rats, whose plasma glucose levels even fell below the starting value at $10 \mathrm{~min}(p<0.005$ by paired Student's t-test), in spite of a very small insulin response (Fig.3).

After intravenous injection of insulin, plasma glucose levels fell by a maximum of about $2.5 \mathrm{mmol} / \mathrm{l}$ at 20 min both in P 15 and P 5 rats (Fig. 3). This decrease corresponded to $45 \pm 3 \%$ and $63 \pm 2 \%(p<0.001)$ of the starting value in P 15 and P 5 rats respectively. Subsequently, return to control values was rapid and complete in P 15 rats, but was very slow and incomplete in $P 5$ rats. Although average plasma glucose levels remained lower in $(\mathrm{P} 5 \rightarrow \mathrm{P} 15)$ rats than in $\mathrm{P} 15$ rats, their initial fall and secondary reascension were parallel to those observed in control rats.

\section{Discussion}

It is known [21] that young rats given a low protein-diet voluntarily reduce their food intake. In another study from this laboratory, this decrease amounted to $35 \%$ [22]. The present experimental model, therefore, does not produce selective protein deficiency but a mixed protein-calorie malnutrition.

Tolerance to oral glucose was slightly poorer in rats fed a low protein diet for 11 weeks than in control rats. However, those animals could hardly be considered glucose-intolerant. Only the increase in glucose levels above the low fasting levels was larger than in control rats. In two previous studies $[14,18]$ rats on a low protein diet for 3 or 4 weeks only showed mild intolerance to oral glucose, absolute plasma levels being transiently higher than in control rats. At variance with the diminished tolerance to intravenous glucose measured in rats malnourished for only 3 weeks [14], we found a slightly better tolerance in rats maintained on a low protein diet for 11 weeks. In two other studies performed after 12-14 weeks of protein-deprivation [15, 16] no alteration of the IVGTT was noted. It is improbable that small differences in protein content of the test diets (4-6\%) can explain these discrepancies, which are more likely to be due to the duration of protein deprivation as discussed later.

The differences in glucose tolerance that we observed in protein-deficient rats according to the route of glucose administration cannot be accounted for by differences in the insulin responses, as they were low during both tests. One can only suggest that proteindeprivation differently affects glucose handling by the liver and peripheral tissues, the relative contribution of which to glucose disposal may differ after oral or intravenous administration [23, 24]. Since magnesium-deficiency is often associated with protein-calorie malnutrition [25], it is interesting to point out that poorer tolerance to oral glucose and better tolerance to intravenous glucose, with low insulin responses during both tests, were also observed in chronically Mg-deficient rats [26].

In agreement with previous reports [14-16, 27], protein-calorie deficient rats consistently exhibited a very poor insulin response to glucose. Arginine and glucagon in the present study, as well as tolbutamide and aminophylline in a previous study [14], also proved to be weak insulin secretagogues in these animals. This impairment of insulin release was much more important than the small decrease in insulin reserves, and persisted even when the concentration of pancreatic insulin had been restored by protein refeeding. Since a similarly low responsiveness of $B$ cells could also be evidenced with isolated islets [15] or the perfused pancreas [16] there seems to be little doubt that proteincalorie malnutrition causes a generalised insensitivity of B cells.

Both under resting and test conditions, malnourished rats succeeded in maintaining a low or near normal glycaemia with low plasma insulin levels. This attests to their high sensitivity to insulin. Moreover, exogenous insulin caused a long-lasting hypoglycaemia that suggests an impairment of the release or of the efficacy of counterregulatory hormones. Their pancreatic stores [17] and their fasting plasma glucagon levels $[17,28]$ are not lower than in control animals. Other counterregulatory hormones are also unlikely to be lacking [5,6]. On the other hand, impaired glucagon efficacy is suggested by our data showing that plasma glucose levels rose only slightly during a glucagon test, in spite of high hepatic glycogen stores. This could be due to the low activity of glucose-6-phosphatase in the liver of protein-deficient animals [5].

Measurements of fasting plasma glucose, insulin and glucagon levels in rats have recently prompted the suggestion [17] of a progressive adaptation of the endocrine pancreas to long-term protein deficiency, the metabolic priority being given to survival and growth to the detriment of glucose homeostasis during the first weeks of deprivation. Evidence that glucose tolerance tests are more severely altered in animals deprived of protein for 3-4 weeks only [14, 18, 27] than in animals malnourished for more than 10 weeks $[15,16$, this study] is in agreement with that suggestion. However, our data also show that this adaptation is practically complete after 11 weeks on a low protein diet, since the changes in glucose tolerance remained essentially similar after that time. It is particularly relevant to emphasize that no spontaneous deterioration occurred with time.

The reversibility of the alterations in glucose homeostasis induced by protein-calorie malnutrition has been investigated in only one recent study [27]. It was shown that 6 weeks on a control diet normalised the tolerance to intraperitoneal glucose, but did not restore a normal insulin response in rats given a low protein 
diet for 3 weeks after weaning. In the present study, 9-12 weeks on a control diet partially reversed the changes in oral or intravenous glucose tolerance produced by 11 weeks of protein-calorie deprivation. On the other hand, the poor insulin response to glucose or glucagon improved only slightly or not at all. The present study and that of Swenne et al. [27] therefore indicate that protein-calorie malnutrition in young rats causes a persistent alteration in insulin release associated with a persistent high tissue sensitivity to insulin. This contrasts with the apparently complete reversibility of the efficacy of counterregulatory hormones, as shown by the normal hyperglycaemic response to glucagon and normal recovery from insulin-induced hypoglycaemia.

In conclusion, chronic protein-calorie malnutrition affects several aspects of glucose homeostasis in the rat. It mainly causes a severe and poorly reversible impairment of insulin release, which does not lead to progressive deterioration of glucose tolerance because of a high sensitivity of the tissues to the hormone. It remains possible, however, that long-lasting malnutrition also increases the vulnerability of B cells; and thereby facilitates development of diabetes on particular genetic backgrounds, in the presence of insulin resistance, during increased demands, or after toxic or viral aggression.

Acknowledgements. We are grateful to Professor A. E. Lambert for continuous support, to A. M. Pottier and M. Gérard for invaluable assistance and to M.Detaille for editorial help. We also thank Dr. L. Hue for advice with the glycogen assay. WO is supported by a fellowship of the AGCD, Brussels, and JCH is "Maître de Recherches" of the FNRS, Brussels.

\section{References}

1. Kahn E, Wayburne S (1960) Hypoglycaemia in patients suffering from advanced protein malnutrition (kwashiorkor). Proc Nutr Soc S Afr 1: 21-23

2. Slone D, Taitz LS, Gilchrist GS (1961) Aspects of carbohydrate metabolism in kwashiorkor with special reference to spontaneous hypoglycemia. Br Med J 1: 32-64

3. Bowie MD (1964) Intravenous glucose tolerance in kwashiorkor and marasmus. S Afr Med J 38: 328-329

4. Baig HA, Edozien JC (1965) Carbohydrate metabolism in kwashiorkor. Lancet ii: $662-665$

5. Heard CRC (1978) The effects of protein-energy malnutrition on blood glucose homeostasis. World Rev Nutr Diet 30: 107-147

6. Becker DJ (1983) The endocrine responses to protein calorie malnutrition. Annu Rev Nutr 3: 187-212

7. Rao RH (1984) The role of undernutrition in the pathogenesis of diabetes mellitus. Diabetes Care 6: 595-601

8. WHO Study Group on diabetes mellitus (1985) WHO Technical Report Series 727

9. Mohan V, Ramachandran A, Viswanathan M (1985) Tropical diabetes. In: Alberti KGMM, Krall LP (eds) The diabetes annual 1. Elsevier, Amsterdam, pp 82-92

10. Abu-Bakare A, Gill GV, Taylor R, Alberti KGMM (1986) Tropical or malnutrition-related diabetes: a real syndrome? Lancet $\mathrm{i}$ : $1135-1138$
11. Heard CRC (1966) Effects of severe protein-calorie deficiency on the endocrine control of carbohydrate metabolism. Diabetes 15 : $78-89$

12. Heard CRC, Turner MR (1967) Glucose tolerance and related factors in dogs fed diets of suboptimal protein value. Diabetes 16: $96-107$

13. Khardori R, Bajaj JS, Deo MG, Bansal DD (1980) Insulin secretion and carbohydrate metabolism in experimental protein malnutrition. J Endocrinol Invest 3: 273-278

14. Weinkove C, Weinkove EA, Pimstone BL (1976) Glucose tolerance and insulin release in malnourished rats. Clin Sci Mol Med 50: 153-163

15. Younoszai R, Dixit PK (1980) Decreased insulin secretion by isolated pancreatic islets from rats fed $4 \%$ protein diet. Proc Soc Exp Biol Med 164: 317-321

16. Levine LS, Wright PG, Marcus F (1983) Failure to secrete immunoreactive insulin by rats fed a low protein diet. Acta Endocrinol 102: 240-245

17. Dollet JM, Beck B, Villaume C, Max JP, Debry G (1985) Progressive adaptation of the endocrine pancreas during long-term protein deficiency in rats: effects on blood glucose homeostasis and on pancreatic insulin, glucagon and somatostatin concentrations. J Nutr 115: 1581-1588

18. Bhutani V, Kumar V, Misra UK (1975) Effect of inadequate dietary proteins on pancreatic insulin and cAMP levels in rats. Nutr Rep Int 32: 1413-1420

19. Lowry OH, Rosebrough NJ, Farr HL, Randall RF (1951) Protein measurement with the folin phenol reagent. J Biol Chem 193: 265-275

20. Hue L, Bontemps F, Hers HG (1975) The effect of glucose and of potassium ions on the interconversion of the two forms of glycogen phosphorylase and of glycogen synthetase in isolated rat liver preparations. Biochem $\mathbf{J}$ 152: 105-114

21. Phillips LS (1981) Nutrition, metabolism and growth. In: Daughaday WH (ed) Endocrine control of growth. Elsevier, New York, pp 121-173

22. Kalenga M, Henquin JC (1987) Alteration of lung mechanics by protein-calorie malnutrition in weaned rats. Respir Physiol 68: 29-39

23. Cherrington AD, Stevenson RW, Steiner KE, Davis MA, Myers SR, Adkins BA, Abumrad NN, Williams PE (1987) Insulin, glucagon and glucose as regulators of hepatic glucose uptake and production in vivo. Diabetes/Metabolism Reviews 3: 307-332

24. De Fronzo RA, Ferrannini E (1987) Regulation of hepatic glucose metabolism in humans. Diabetes/Metabolism Reviews 3: 415-459

25. Caddell JL, Goddard DR (1967) Studies in protein-calorie malnutrition. I: Chemical evidence for magnesium deficiency. $\mathrm{N}$ Engl J Med 276: 533-540

26. Legrand C, Okitolonda W, Pottier AM, Lederer J, Henquin JC (1987) Glucose homeostasis in magnesium-deficient rats. Metabolism 36: $160-164$

27. Swenne I, Crace CJ, Milner RDG (1987) Persistent impairment of insulin secretory response to glucose in adult rats after limited period of protein-calorie malnutrition early in life. Diabetes 36 : 454-458

28. Anthony LE, Faloona GR (1974) Plasma insulin and glucagon levels in protein-malnourished rats. Metabolism 23:303-306

Received: 16 June 1987

and in revised form: 27 October 1987

Dr. J.C.Henquin

Unité de Diabétologie et Nutrition

UCL 54.74

Avenue Hippocrate, 54

B-1200 Brussels

Belgium 